\title{
Analisis Kondisi Keuangan Pemerintah Kabupaten Di Kalimantan
}

\author{
Ika Kurnia Indriani ${ }^{1)}$, Melati Pramudita Lestari ${ }^{2}$, MerryTriani $^{3)}$ \\ ${ }^{1}$ Prodi Akuntansi Sektor Publik, Politeknik Negeri Pontianak, \\ Email: ikakurniaindriani@gmail.com \\ ${ }^{2}$ Prodi Akuntansi Sektor Publik, Politeknik Negeri Pontianak, \\ Email: melatipramudita@yahoo.com \\ ${ }^{3}$ Prodi Akuntansi Sektor Publik, Politeknik Negeri Pontianak, \\ Email: merrytriani@yahoo.com
}

\begin{abstract}
An assessment of the financial condition of district governments in Kalimantan will provide an early warning to implement good regional financial management, so that regional financial health can be maintained. An analysis of the financial condition of district governments on the island of Kalimantan has never been carried out. The $A P B D$ is one of the stimuli used by district governments to encourage regional economic growth. Therefore, based on this phenomenon, it is necessary to analyze the financial condition of the district government in all regions of Kalimantan. This study uses a descriptive quantitative approach using the method of budget solvency, service solvency, and financial independence. The data used is secondary data, namely the 2014-2018 Budget Realization Report. The study population was 37 district governments on the island of Kalimantan. The research sample was 185 samples. The results of the research by the Government of Mahakam Ulu Regency which is located in East Kalimantan Province and Sekadau Regency in West Kalimantan Province have the highest budget solvency, while the solvency of Sambas Regency in West Kalimantan and Kutai Kartanegara in East Kalimantan has the lowest budget solvency. The best financial independence in all districts in Kalimantan was obtained by Penajam Paser Utara District in East Kalimantan and Lamandau District in Central Kalimantan. The lowest level of financial independence was obtained by Kayong Utara District, West Kalimantan and Mahakam Ulu Regency, East Kalimantan. Tana Tindung and Mahakan Ulu districts had the highest service solvency, while Kubu Raya and Sambas districts had the lowest solvency.
\end{abstract}

Keywords: Budgetary Solvency, Financial Independence, Service-Level Solvency, and District Governments.

\begin{abstract}
Abstrak
Penilaian atas kondisi keuangan pemerintah kabupaten di Kalimantan akan memberikan sebuah peringatan dini agar melaksanakan pengelolaan keuangan daerah yang baik, agar kesehatan keuangan daerah dapat terjaga. Analisis kondisi keuangan Pemerintah Kabupaten di Pulau Kalimantan belum pernah dilaksanakan. APBD merupakan salah satu stimulus yang digunakan oleh pemerintah kabupaten untuk mendorong pertumbuhan ekonomi daerah. Oleh karena itu berdasarkan fenomena ini perlu dilakukan analisis kondisi keuangan pemerintah Kabupaten di seluruh wilayah Kalimantan. Penelitian ini menggunakan pendekatan kuantitatif deskriptif dengan menggunakan metode solvabilitas anggaran, solvabilitas layanan, dan kemandirian keuangan. Data yang digunakan adalah data sekunder yaitu Laporan Realisasi Anggaran selama tahun 2014-2018. Populasi penelitian ini 37 Pemerintah kabupaten yang ada di pulau Kalimantan. Sample penelitian sebanyak 185 data. Hasil penelitian Pemerintah Kabupaten Mahakam Ulu yang terletak di Provinsi Kalimantan Timur dan dan Kabupaten Sekadau di Provinsi Kalimantan Barat memiliki solvabilitas anggaran tertinggi, sedangkan solvabilitas Kabupaten Sambas di Kalimantan Barat dan Kutai Kartanegara di Kalimantan Timur memiliki solvabilitas anggaran terendah. Kemandirian keuangan terbaik di seluruh kabupaten di Kalimantan diperoleh oleh Kabupaten Penajam Paser Utara di Kalimantan Timur dan Kabupaten Lamandau di Kalimantan Tengah. Tingkat kemandirian keuangan terendah diperoleh oleh Kabupaten Kayong Utara Kalimantan Barat dan Kabupaten Mahakam Ulu Kalimantan Timur. Kabupaten Tana Tindung dan Kabupaten Mahakan Ulu memiliki solvabilitas layanan tertinggi, sedangkan Kabupaten Kubu Raya dan Kabupeten Sambas memiliki solvabilitas terendah.
\end{abstract}

Kata Kunci: Solvabilitas Anggaran, Kemandirian Keuangan, Solvabilitas Layanan, dan Pemerintah Kabupaten.

\section{PENDAHULUAN}

Indonesia merupakan negara demokrasi yang yang menerapkan sistem otonomi daerah dengan berasaskan desentralisasi fiskal. Penyelenggaraan pemerintah daerah yang berbasis dengan otonomi daerah ditujukan untuk mendekatkan masyarakat kepada pemerintah agar pelayanan publik menjadi optimal. Pemerintah daerah berperan penting dalam proses pelaksanaan otonomi daerah agar membawa dampak positif pada pertumbuhan ekonomi dan pencapaian tujuan negara. Pemerintah kabupaten bertugas melaksanakan otonomi daerah, sebagai wilayah administratif yang bertugas langsung dalam melaksanakan pelayanan publik. 
Tidak terkecuali Pemerintah Kabupaten yang berada di Pulau Kalimantan dengan karakteristik yang unik. Pulau Kalimantan adalah sebuah pulau yang terletak di tengah wilayah Indonesia dan merupakan pulau terbesar ketiga di dunia ini di Indonesia. Pulau Kalimantan merupakan pulau terbesar di Indonesia secara administratif terbagi dalam 5 Provinsi dengan 48 Kabupaten dan 9 Kota (BPS, 2020). Jumlah penduduk yang relatif cukup besar yaitu 15.343.000 (BPS, 2020) menimbulkan kesenjangan pertumbuhan ekonomi di Pulau Kalimantan. Kalimantan Timur merupakan wilayah dengan pertumbuhan ekonomi tertinggi dibandingkan wilayah Kalimantan lainnya. Pertumbuhan ekonomi Kabupaten di Kalimantan ditopang oleh bidang pertanian, perkebunan, dan pertambangan.

Ketimpangan pertumbuhan ekonomi dapat dipicu oleh ketimpangan pembangunan infrastruktur pelayanan dasar antar wilayah di Kalimantan. Adanya indikasi ketimpangan di Kalimantan, disebabkan oleh disparitas pembangunan antar wilayah di Kalimantan. Khususnya bagi wilayah penghasil migas dan nonpenghasil Migas, maupun antar kawasan perkotaan dengan kawasan pedesaan. Pada umumnya pembangunan di wilayah kabupaten di Kalimantan masih sangat lambat. Hal ini dikarenakan jumlah alokasi dana untuk belanja daerah khususnya kesejahteraan masyarakat pulau Kalimantan sangatlah sedikit, ini tidak sebanding dengan yang jumlah kekayaan alam yang dieksploitasi dari tanah Kalimantan. Kondisi ini dapat dikatakan bahwa kekayaan sumber daya alam di Pulau Kalimantan belum berkorelasi positif dengan kesejahteraan masyarakatnya (Kuncoro, 2014). Berdasarkan data pertumbuhan ekonomi terendah pada tahun 2008 terdapat di Kabupaten Mempawah dan Kabupaten Landak, Provinsi Kalimantan Barat (Kuncoro, 2014). Kabupaten Kotawaringin Timur, Provinsi Kalimantan Tengah merupakan kabupaten dengan tingkat kemiskinan tertinggi (Kuncoro, 2014).

Kondisi ini mendorong diperlukannya sebuah analisis kondisi keuangan agar di masa yang akan datang Pemerintah Kabupaten di pulau Kalimantan. Tujuannya agar Kabupaten di Kalimantan dapat mengembangkan dan memaksimalkan potensi yang dimiliki, untuk mencapai pertumbuhan ekonomi yang merata. Metode yang dapat digunakan dalam analisis kondisi keuangan adalah solvabilitas anggaran, solvabilitas layanan dan kemandirian keuangan pemerintah Kabupaten. Metode ini dikenal dengan analisis kondisi keuangan pemerintah (Ritonga, 2014). Analisis kondisi keuangan bertujuan untuk memberikan peringatan dini kepada pemerintah kabupaten agar melaksanakan pengelolaan keuangan daerah yang baik, agar kesehatan keuangan daerah dapat terjaga. Analisis kondisi keuangan Pemerintah Kabupaten di Pulau Kalimantan belum pernah dilaksanakan. APBD merupakan salah satu stimulus yang digunakan oleh pemerintah kabupaten untuk mendorong pertumbuhan ekonomi daerah.

\section{LANDASAN TEORI DAN PENGEMBANGAN HIPOTESIS}

Penilaian kondisi keuangan pemerintah daerah dilakukan dengan menggunakan tiga indikator. Ketiga indikato ini akan menilai kemanpuan pemeintah daerah dalam memenuhi kewajiban kepada masyarakat. Pemerintah daerah yang memiliki pengelolaan keuangan yang baik, akan memiliki kondisi keuangan yang baik.

a. Solvabilitas Anggaran

Solvabilitas anggaran menunjukkan kemampuan pemerintah daerah untuk mendapatkan pendapatan untuk mendanai operasinya selama satu periode anggaran keuangan. (Nollenberger et.al.,2003 dalam Ritonga, 2014:142)

b. Kemandirian Keuangan

Kemandirian keuangan adalah suatu kondisi dimana pemerintah daerah tidak rentan terhadap sumber pendanaan luar kendalinya atau pengaruhnya, baik sumber pendanaan nasional dan internasional (CICA, 1997 dalam Ritonga, 2014).

c. Solvabilitas Layanan

Solvabilitas layanan menunjukkan kemampuan pemda untuk menyediakan dan mempertahankan kualitas pelayanan publik yang dibutuhkan dan diinginkan oleh masyarakat (Wang, et. Al., 2007 dalam Ritonga, 2014:181). 
Prosedur analisis kondisi keuangan yang diangkat oleh peneliti berdasarkan kepada metode penilaian kondisi keuangan pemerintah daerah (Ritonga, 2014). Analisis terdapat terhadap kondisi keuangan pemerintah kabupaten di Kalimantan dilakukan dalam tiga. Tahap pertama yaitu menentukan kelompok acuan pemerintah daerah di mana dilakukan benchmark terhadap pemerintah daerah lain. Pemerintah Daerah yang dipilih yaitu memiliki tipe pemerintah daerah yang sama. Khusus pada penelitian ini dilakukan analisa kondisi keuangan pemerintah daerah kepada seluruh pemerintah kabupaten yang ada di Pulau Kalimantan. Analisis ini dilakukan kepada seluruh pemerintah kabupaten berdasarkan laporan realisasi anggaran tahun 2014 hingga tahun 2018. Tahap kedua, menghitung rasio masing-masing Kabupaten. Perhitungan menggunaan teknik analisis dengan rasio solvabilitas anggaran, rasio kemandirian keuangan, dan rasio solvabilitas layanan. Perhitungan rasio akan dilanjutkan dengan analisis statistik deskriptif. Tahap ketiga, menghitung indeks indikator metode perhitungan indeks indikator dikembangkan oleh Perserikatan Bangsa-Bangsa (Ritonga, 2014). Hal ini disebabkan oleh nilai satuan dimensi dan indikator kondisi keuangan yang berbedabeda. Transformasi data yang dilakukan biasanya dalam bentuk eksponensial dan logaritma ataupun bentuk lainnya. Hal ini dilakukan untuk meminimalisir adanya variasi data yang ekstrim. Indeks dimensi merupakan rata-rata aritmatika dari indeks indikator yang membentuknya (Ritonga, 2014). Penggunaan rata-rata aritmatika akan menghasilkan sebuah data yang lebih adil dan dan lebih mudah untuk dianalisa. Penghitungan indeks dimensi akan menghasilkan nilai minimum yaitu 0 dan nilai maksimum yaitu 1 sehingga hasilnya akan mudah dianalisis pada saat proses pengambilan keputusan di akhir nanti.

\section{HASIL DAN PEMBAHASAN}

Statistik deskriptif terhadap solvabilitas anggaran pada rasio A, B, C, dan D menunjukan bahwa data tidak terdistribusi dengan normal. Hal ini ditunjukkan dengan nilai skewness sebesar 5,81; 1,39;2,63 dan 4,12. Nilai kurtosis pada solvabilitas anggaran untuk rasio A sebesar 46,26; rasio B 6,98; rasio C 14,72; dan rasio D 32,40. Nilai median pada perhitungan rasio solvabilitas anggaran untuk rasio A sebesar 1,21 rasio B 1,20 rasio $\mathrm{C}$ 2,50 dan rasio $\mathrm{D}$ 0,99. Nilai median adalah statistik yang lebih baik untuk mempresentasikan populasi. Berdasarkan perhitungan rasio solvabilitas anggaran dapat disimpulkan bahwa Pemerintah Kabupaten di Kalimantan memiliki solvabilitas anggaran yang cukup baik. Masing-masing Pemerintah Kabupaten memiliki pendapatan yang cukup untuk menutupi biaya operasional mereka.

Statistik deskriptif kemandirian keuangan menunjukkan bahwa data rasio A dan rasio B menunjukan data tidak terdistribusi secara normal. Ini terlihat dengan nilai skewness sebesar 1,10 dan 1,24. Nilai kurtosis pada rasio A dan rasio B sebesar 4,44 dan 4,68. Oleh karena itu nilai median adalah statistik yang lebih baik untuk mencerminkan populasi. Median dari rasio A dan B adalah 5,94\% dan 5,89\%. Kondisi ini menggambarkan bahwa hanya sekitar 5,9\% dari pendapatan Pemerintah Kabupaten di Kalimantan berada di bawah kendali mereka. Hal ini dapat dikatakan bahwa pemerintah daerah sangat bergantung pada sumber pendanaan dari luar, yang mereka tidak mampu mengendalikannya. Berdasarkan perhitungan rasio kemandirian keuangan menunjukkan bahwa Pemerintah Kabupaten diKalimantan memiliki kemandirian keuangan yang lemah.

Perhitungan rasio solvabilitas layanan Pemerintah Kabupaten di Kalimantan tahun anggaran 2014-2018 menggunakan Laporan Realisasi Anggaran. Oleh karena itu hanya rasio $\mathrm{D}$ dan rasio $\mathrm{F}$ yang dapat dihitung dengan membandingkan total belanja dan total belanja modal terhadap jumlah penduduk di wilayah kabupaten masing-masing. Berdasarkan hasil analisis statistik deskriptif pada solvabilitas layanan rasio D dan rasio F nilai skewness sebesar 3,17 dan 3,97. Nilai kurtosis sebesar 14,03 untuk rasio D dan rasio F 22,62. Hal ini menunjukkan bahwa rasio A dan rasio B tidak terdistribusi secara normal. Oleh karena itu nilai median adalah statistic yang lebih tepat untuk merepresentasikan populasi. Median untuk ratio D dan rasio F menunjukkan Pemerintah Kabupaten di Kalimantan memiliki total belanja sebesar Rp 
6.616.088 dan total belanja modal Rp1.648.119 untuk menyelenggarakan pelayanan publik bagi setiap warga masyarakat. Rasio solvabilitas layanan tidak dapat disimpulkan apakah kondisi tersebut baik atau tidak karena tidak ada acuan penilaian yang baku untuk dimensi ini. Namun secara umum semakin tinggi rasio solvabilitas layanan Pemerintah Kabupaten di Kalimantan maka akan semakin baik pula solvabilitas layanan pemerintah kepada masyarakat.

Tabel 1. Statistik Deskriptif Kondisi Keuangan Pemerintah Kabupaten di Kalimantan

\begin{tabular}{|c|c|c|c|c|c|c|c|c|}
\hline \multirow[t]{2}{*}{ Indikator } & \multicolumn{4}{|c|}{ Solvabilitas Anggaran } & \multicolumn{2}{|c|}{ Kemandirian Keuangan } & \multicolumn{2}{|c|}{ Solvabilitas Layanan } \\
\hline & Rasio A & Rasio B & Rasio C & Rasio D & $\begin{array}{c}\text { Rasio } \\
\text { A }\end{array}$ & Rasio B & Rasio D & Rasio F \\
\hline Mean & 1.273 & 1.237 & 2.656 & 0.996 & 0.067 & 0.067 & 8568229 & 2655546 \\
\hline Median & 1.214 & 1.209 & 2.504 & 0.992 & 0.059 & 0.058 & 6616088 & 1648116 \\
\hline Maximum & 4.344 & 2.335 & 7.592 & 2.087 & 0.187 & 0.181 & $\begin{array}{c}5140696 \\
9 \\
\end{array}$ & $\begin{array}{c}2646448 \\
9\end{array}$ \\
\hline Minimum & 0.854 & 0.854 & 1.549 & 0.553 & 0.004 & 0.007 & 1905975 & $\begin{array}{c}255069 . \\
0\end{array}$ \\
\hline Std. Dev. & 0.381 & 0.206 & 0.738 & 0.151 & 0.033 & 0.034 & 8297030 & 3351799 \\
\hline Skewness & 5.813 & 1.398 & 2.637 & 4.125 & 1.104 & 1.245 & $\begin{array}{c}3.17332 \\
8\end{array}$ & $\begin{array}{c}3.97980 \\
3\end{array}$ \\
\hline Kurtosis & 46.26 & 6.984 & 14.723 & 32.400 & 4.445 & 4.685 & $\begin{array}{c}14.0357 \\
3\end{array}$ & $\begin{array}{c}22.6215 \\
7\end{array}$ \\
\hline Jarque-Bera & $\begin{array}{c}15471.5 \\
2\end{array}$ & 182.70 & 1273.84 & 7187.78 & 53.708 & 69.734 & $\begin{array}{c}1249.27 \\
0\end{array}$ & $\begin{array}{c}3456.12 \\
0\end{array}$ \\
\hline Probability & 0.000 & 0.000 & 0.000 & 0.000 & 0.000 & 0.000 & $\begin{array}{c}0.00000 \\
0\end{array}$ & $\begin{array}{c}0.00000 \\
0\end{array}$ \\
\hline Sum & 235.515 & 228.846 & 491.537 & 184.28 & 12.518 & 12.457 & $\begin{array}{c}1.59 \mathrm{E}+0 \\
9\end{array}$ & $\begin{array}{c}4.91 \mathrm{E}+0 \\
8\end{array}$ \\
\hline Sum Sq. Dev. & 26.823 & 7.854 & 100.268 & 4.21577 & 0.203 & 0.224 & $\begin{array}{c}1.27 \mathrm{E}+1 \\
6\end{array}$ & $\begin{array}{c}2.07 \mathrm{E}+1 \\
5\end{array}$ \\
\hline Observations & 185 & 185 & 185 & 185 & 185 & 185 & 185 & 185 \\
\hline
\end{tabular}

Nilai median pada solvabilitas anggaran menunjukkan adanya tren penurunan, di mana rasio A pada tahun 2014 sebesar 1,41\% sedangkan tahun 2018 mengalami penurunan menjadi 1,09\%. Kondisi ini menunjukkan bahwa solvabilitas anggaran Pemerintah Kabupaten di Kalimantan cenderung menurun dari rentang waktu 2014 hingga tahun 2018. Meskipun rasiorasio sabilitas Anggaran menunjukkan tren penurunan namun Pemerintah Kabupaten di Kalimantan masih memiliki kemampuan untuk menutupi belanja mereka. Pemerintah Kabupaten harus berhati-hati di tahun-tahun mendatang karena devisi keuangan merupakan permulaan terjadinya kesulitan keuangan di masa yang akan datang (Ritonga, 2014).

Nilai median kemandirian keuangan Pemerintah Kabupaten di Kalimantan ditunjukkan oleh rasio A dan rasio B. Jika dilihat dari tren yang selama tahun 2014 hingga 2018 menunjukkan sebuah kondisi keuangan yang stabil dalam aspek kemandirian keuangan. Tingkat kemandirian keuangan Pemerintah Kabupaten di Kalimantan tergolong lemah. Hal ini terlihat dari nilai Rasio A tahun 2014 hanya sebesar 0,06 dan mengalami peningkatan yang tidak kecil pada tahun 2018 menjadi 0,08. Hal ini mengidikasikan bahwa pendapatan asli daerah maupun sumber pendapatan daerah lainnya belum optimal dalam membiayai aktifitas pembangunan daerah, sehingga daerah masih sangat bergantung dengan adanya subsidi pemerintah melalui Dana Perimbangan. (Bisma et al, 2010). Pendapatan Asli daerah tidak berpengaruh terhadap belanja daerah, sedangkan DAU berpengaruh terhadap belanja daerah dan DAK berpengaruh terhadap belanja daerah pemerintah kabupaten/kota (Amalia, 2015). Kondisi ini membuktikan bahwa kemandirian keuangan daerah masih rendah karena tingkat ketergantungan pemerintah daerah 
terhadap dana transfer dari pemerintah pusat sangat tinggi (Amalia, 2015).

Kemandirian keuangan yang lemah dapat disebabkan oleh kebijakan yang terdapat dalam konstitusi Indonesia. Undang-Undang Dasar 1945 Pasal 33 menyatakan bahwa seluruh sumber daya alam yang dimiliki oleh negara yang mempengaruhi kehidupan rakyat dikendalikan oleh pemerintah pusat. Ini berdampak kepada sumber strategis penerimaan seperti pajak penghasilan dan pajak pertambahan nilai meskipun sumber-sumber tersebut terletak di wilayah Pemerintah kabupaten, menjadi sumber pendapatan bagi pemerintah pusat. Pemerintah kabupaten hanya mengelola sumber pendapatan non strategis, sehingga tidak berpengaruh secara signifikan keuangan daerah terhadap kehidupan masyarakat. Hal ini mengakibatkan rendahnya kemandirian keuangan Pemerintah Kabupaten di Kalimantan. Undang-undang 32 tahun 2004 tentang pemerintah daerah dan undang-undang Nomor 33 tahun 2004 tentang perimbangan keuangan menjelaskan bahwa pemerintah daerah tetap dituntut untuk meningkatkan melalui inovasi. Inovasi ini tetap diatur di dalam peraturan undang-undang sehingga tidak ada yang bertentangan. Kemampuan inovasi untuk meningkatkan pendapatan aslidaerah tentunya bervariasi antar pemerintah daerah.

Peningkatan Pendapatan asli daerah akan meningkatkan kapasitas pemerintah daerah untuk mendanai program kegiatanpelayanan kepada masyarakat. Oleh karena itu pemerintah daerah dengan kemampuan pendapatan asli daerah yang kuat akan memiliki kondisi keuangan yang baik pula (Ritonga, 2014). Keterbatasan pemerintah daerah dalam mengali potensi ekonomi memang disebabkan oleh konstitusi Indonesia yang mengatur hal tersebut adanya kebijakan otonomi daerah tidak serta merta menjadikan daerah mandiri dan mampu membiayai segala aktifitas pembangunan daerah melalui optimalisasi perolehan sumbersumber pendapatan daerah (Bisma et al, 2010).Nilai median solvabilitas layanan menunjukan tren penurunan. Nilai rasio D pada tahun 2014 adalah Rp5.992.736,50 perpenduduk, pada tahun 2018 mengalami penurunan menjadi Rp6.855.026,67 per kapita. Nilai rasio Fpada tahun 2014 adalah Rp1.757.108,17 dan menurun pada tahun 2018 menjadi Rp1.474.592,58. Secara umum nilai median solvabilitas layanan Pemerintah Kabupaten di Kalimantan tahun 2014 hingga 2018 sesungguhnya mengalami fluktuasi. Dimana pada tahun 2015-2016 mengalami peningkatan, namun pada tahun 2017-2018 mengalami penurunan.

Kondisi ini menunjukkan adanya penurunan pelayanan yang diberikan kepada masyarakat dalam kurun waktu 2014 hingga tahun 2018. Pemerintah Kabupaten di Kalimantan pernah mencapai nilai terbaik pada tahun 2015-2016 untuk solvabilitas layanan. Hal ini menunjukkan bahwa pemerintah kabupaten masih belum bisa mempertahankan kualitas pelayanan publik yang diharapkan dan dibutuhkan oleh masyarakat. Pelaksanaan otonomi daerah, secara empiris juga membawa perubahan dan inovasi dari sistem penyelenggaraan pemerintahan daerah pada pelayanan publik. Hal ini disebabkan oleh pemerintah daerah sebagai ujung tombak yang berfungsi sebagai pengayom, pembina, pelayan, penggerak partisipasi masyarakat (fatnuriawan, 2014).

Tabel 2. Nilai Median Rasio Solvabilitas Anggaran Pemerintah Kabupaten di Kalimantan

\begin{tabular}{|c|c|c|c|c|c|c|c|c|}
\hline \multirow{2}{*}{ Tahun } & \multicolumn{4}{|c|}{ Solvabilitas Anggaran } & Kemandirian Keuangan & \multicolumn{2}{c|}{ Solvabilitas Layanan } \\
\cline { 2 - 9 } & Rasio A & Rasio B & Rasio C & Rasio D & Rasio A & Rasio B & Rasio D & Rasio F \\
\hline 2014 & 1,41 & 1,41 & 2,58 & 1,02 & 0,06 & 0,06 & $5.992 .736,50$ & $1.757 .108,17$ \\
\hline 2015 & 1,25 & 1,25 & 2,50 & 0,98 & 0,05 & 0,05 & $7.226 .493,18$ & $2.109 .103,32$ \\
\hline 2016 & 1,18 & 1,17 & 2,43 & 0,99 & 0,05 & 0,05 & $7.048 .535,28$ & $1.900 .305,21$ \\
\hline 2017 & 1,09 & 1,09 & 2,50 & 0,99 & 0,08 & 0,07 & $6.418 .815,84$ & $1.603 .356,02$ \\
\hline 2018 & 1,09 & 1,09 & 2,50 & 0,99 & 0,08 & 0,07 & $6.855 .026,67$ & $1.474 .592,58$ \\
\hline
\end{tabular}


Tabel 3. Indeks Dimensi Solvabilitas Anggaran Nilai Tertinggi dan Nilai Terendah

\begin{tabular}{|c|c|c|c|c|}
\hline Tahun & Nama Kabupaten & Tertinggi & Nama Kabupaten & Terendah \\
\hline 2014 & Mahakam Ulu & 0,69 & Sambas & 0,03 \\
\hline 2015 & Kutai Barat & 0,81 & Bulungan & 0,03 \\
\hline 2016 & Mahakan Ulu & 0,86 & Sambas & 0,12 \\
\hline 2017 & Sekadau & 0,75 & Kutai Kartanegara & 0,05 \\
\hline 2018 & Sekadau & 0,70 & Kutai Kartanegara & 0,05 \\
\hline
\end{tabular}

Perhitungan indeks dimensi solvabilitas anggaran Pemerintah Kabupaten di Kalimantan menunjukkan bahwa pemerintah Kabupaten Mahakam Ulu, Pemerintah Kabupaten Kutai Barat, dan Pemerintah Kabupaten Sekadau merupakan Pemerintah Kabupaten dengan tingkat solvabilitas anggaran tertinggi. Hal ini mengindikasikan bahwa kemampuan Pemerintah Kabupaten Mahakam Ulu Kutai Barat dan Kabupaten Sekadau dalam mengelola sumber pendapatannya cukup optimal sehingga dapat mendanai operasinya selama satu periode anggaran. Sedangkan Pemerintah Kabupaten Sambas Pemerintah Kabupaten Bulungan dan pemerintah Kabupaten Kutai Kartanegara merupakan Pemerintah Kabupaten dengan solvabilitas anggaran terendah. Ini mengindikasikan bahwa ketika kabupaten tersebut masih belum optimal dalam mengelola sumber pendapatannya dalam mendanai operasinya selama satu periode anggaran.

Tabel 4. Indeks Dimensi Kemandirian Keuangan Nilai Tertinggi dan Nilai Terendah

\begin{tabular}{|c|c|c|c|c|}
\hline Tahun & Nama Kabupaten & Tertinggi & Nama Kabupaten & Terendah \\
\hline 2014 & Kotawaringin Barat & 1,00 & Mahakam Ulu & 0,00 \\
\hline 2015 & Kotawaringin Barat & 0,96 & Mahakam Ulu & 0,00 \\
\hline 2016 & Penajam Paser Utara & 1,00 & Kayong Utara & 0,00 \\
\hline 2017 & Lamandau & 1,00 & Mahakam Ulu & 0,00 \\
\hline 2018 & Lamandau & 1,00 & Mahakam Ulu & 0,00 \\
\hline
\end{tabular}

Perhitungan indeks dimensi kemandirian keuangan di seluruh Pemerintah Kabupaten di Kalimantan diperoleh bahwa Pemerintah Kabupaten Kotawaringin Barat Pemerintah Kabupaten Penajam Paser Utara dan pemerintah Kabupaten Lamandau merupakan Pemerintah Kabupaten dengan tingkat kemandirian keuangan tertinggi. Ini mengindikasikan bahwa ketiga Pemerintah Kabupaten ini relatif tidak rentan terhadap sumber pendanaan yang berasal dari dalam negeri maupun luar negeri yang di luar kendalinya dalam memenuhi belanja operasi selama satu periode anggaran. Sedangkan Pemerintah Kabupaten Mahakam Ulu dan pemerintah Kabupaten Kayong Utara merupakan Pemerintah Kabupaten dengan tingkat kemandirian keuangan rendah di Kalimantan. Ini mengindikasikan bahwa pemerintah Kabupaten Mahakam Ulu dan Pemerintah Kabupaten Kayong Utara masih rentan terhadap sumber pendanaan baik dalam negeri ataupun luar negeri dalam memenuhi belanja operasi selama satu periode anggaran. Ketergantungan Keuangan Daerah Sangat Tinggi terhadap Pemerintah Pusat sehingga tingkat Kemandirian Daerah Sangat Kurang (Bisma et al, 2010). Pada akhirnya Pemerintah Kabupaten lebih banyak menggunakan dana transfer berupa DAU dan DAK akan untuk menutupi kebutuhan belanja daerah, selain penggunaan PAD (Amalia et al, 2015). Otonomi daerah dengan berasaskan desentralisasi fiskal membuka peluang bagi pemerintah kabupaten di Kalimantan untuk menggali dan mengoptimalkan penerimaanPAD sesuai potensi daerah yang dimiliki karena semakin tinggi PAD, semakin banyak kebutuhan yang dapat dibiayai oleh PAD (Amalia et al, 2015).

Tabel 5. Indeks Dimensi Solvabilitas Layanan Nilai Tertinggi dan Nilai Terendah

\begin{tabular}{|c|c|c|c|c|}
\hline Tahun & Nama Kabupaten & Tertinggi & Nama Kabupaten & Terendah \\
\hline 2014 & Tana Tindung & 1,00 & Kubu Raya dan Sambas & 0,00 \\
\hline 2015 & Mahakam Ulu & 0,50 & Kabu Raya dan Sambas & 0,00 \\
\hline 2016 & Tana Tindung & 1,00 & Kubu Raya & 0,00 \\
\hline
\end{tabular}




\begin{tabular}{l|l|l|l|l|}
2017 & Mahakam Ulu & 0,87 & Kubu Raya & 0,00 \\
\hline 2018 & Mahakam Ulu & 1,00 & Kubu Raya Dan Sambas & 0,00 \\
\hline
\end{tabular}

Perhitungan indeks dimensi solvabilitas layanan di Pemerintah Kabupaten seluruh Kalimantan, menunjukkan bahwa Kabupaten Tana Tidung dan Kabupaten Mahakam Ulu merupakan Pemerintah Kabupaten yang memiliki tingkat solvabilitas layanan terbaik di seluruh kabupaten yang ada di Kalimantan. Hal ini mengindikasikan bahwa Kabupaten Tana Tidung dan Kabupaten Mahakam Ulu dapat menunjukkan kemampuan dalam menyediakan dan mempertahankan kualitas pelayanan publik yang diinginkan oleh masyarakat. Sedangkan Kabupaten Kubu Raya, Kabupaten Sambas di Provinsi Kalimantan Barat merupakan Pemerintah Kabupaten yang memiliki solvabilitas layanan terendah di seluruh Kalimantan. Hal ini mengindikasikan bahwa Kabupaten Kubu Raya dan Kabupaten Sambas masih memiliki kelemahan dalam memenuhi atau menyediakan kualitas pelayanan publik yang dibutuhkan oleh masyarakat. Banyak kabupaten/kota yang termasuk dalam daerah tertinggal atau 50\% daerah-daerah di Kalimantan tergolong dalam kategori Tertinggal (Kuncoro, 2014).

Hal terpenting dari otonomi daerah adalah terselenggaranya layanan publik terhadap masyarakat dalam rangka pemenuhan kebutuhan masyarakat atau kepentingan umum (Fatnuriawan, 2014). Pelayanan publik merupakan hak dari masyarakat daerah yang memiliki keabsahan untuk dipenuhi sebagaimana yang dikehendaki dan merupakan kewajiban yang harus dilakukan Pemerintah daerah agar bisa memperjuangkan kepentingan umum dengan efektif, efisien dan transparan (Sekeretariat Jendral Depnagri, 2001, dalam Fatnuriawan, 2014). Kinerja aparat pemerintah masih relatif rendah dan belum sepenuhnya bisa memenuhi harapan publik, ketika melaksanakan tugas pokok, fungsi, kewenangan, dan tanggung jawab, terutama dalam menyelenggarakan pemerintahan, pembangunan, dan pelayanan masyarakat (Fatnuriawan, 2014). Pada prinsipnya setiap pelayanan yang diberikan oleh instansi pemerintahan senantiasa harus selalu ditingkatkan kualitasnya sesuai dengan keinginan masyarakat (Fatnuriawan, 2014). Pemerintah Kabupaten di Kalimantan mengalami pemekaran khususnya untuk wilayah Kalimantan Utara. Pada dasarnya pemekaran wilayah bertujuan untuk memperpendek rentang pemerintahan agar tercipta pelayanan publik yang lebih baik dan lebih dekat dengan masyarakat demi terwujudnya masyarakat yang sejahtera (Hakim, 2017). Pemekaran di wilayah Kalimantan diharapkan akan meningkatkan kualitas pelayanan publik di masa mendatang.

\section{KESIMPULAN}

Kondisi keuangan Pemerintah Kabupaten di Kalimantan dari solvabilitas anggaran dapat disimpulkan memiliki solvabilitas anggaran yang cukup baik. Masing- masing pemerintah kabupaten memiliki pendapatan yang cukup untuk menutupi biaya operasional mereka. Kemandirian keuangan pemerintah kabupaten masih sangat bergantung pada sumber pendanaan dari luar, sehingga memiliki kemandirian keuangan yang lemah. Solvabilitas Pemerintah Kabupaten di Kalimantan memiliki total belanja sebesar Rp 6.616.088 dan total belanja modal Rp1.648.119 untuk menyelenggarakan pelayanan publik bagi setiap warga masyarakat. Analisis kondisi keuangan menunjukkan bahwa Pemerintah Kabupaten Mahakam Ulu dan Kabupaten Sekadau di Provinsi Kalimantan Barat memiliki solvabilitas anggaran tertinggi, sedangkan solvabilitas Kabupaten Sambas di dan Kutai Kartanegara memiliki solvabilitas anggaran terendah. Kemandirian keuangan terbaik diperoleh oleh Kabupaten Penajam Paser Utara dan Kabupaten Lamandau. Tingkat kemandirian keuangan terendah adalah Kabupaten Kayong Utara dan Kabupaten Mahakam Ulu. Kabupaten Tana Tindung dan Kabupaten Mahakan Ulu memiliki solvabilitas layanan tertinggi, sedangkan Kabupaten Kubu Raya dan Kabupeten Sambas memiliki solvabilitas terendah. 


\section{DAFTAR PUSTAKA}

Amalia, Wia Rizki,dkk. 2015. Flypaper effect pada pendapatan asli daerah (PAD), dana alokasi umum (DAU) dan dana alokasi KHusus (DAK) terhadap belanja daerah pada pemerintah kabupaten/kota di provinsi Kalimantan selatan 2009-2013. Vol. 15, No. 1. Provinsi Nusa Tenggara Barat : Jurnal Akuntansi dan Bisnis.

Badan Pusat Statistik. https://www.bps.go.id/, di akses pada 5 Agustus 2020.

Bisma, I Dewa Gde, dan Hery Susanto. 2010. Evaluasi Kinerja Keuangan Daerah Pemerintah Provinsi Nusa Tenggara Barat Tahun Anggaran 2003-2007. GaneÇ Swara Edisi Khusus Vol. 4 No.3.

Fatnuriawan, Ayok. 2014. Kinerja Aparatur Pemerintah Desa Dalam Upaya Menigkatkan Mutu Pelayanan Publik Di Desa Puhjarak Kecamatan Plemahan Kabupaten Kediri Tahin 2014. Malang: Universitas Negeri Malang .

Hakim, Abdul. 2017. Analisis Dampak Pemekaran Daerah Ditinjau Dari Aspek Percepatan Pertumbuhan Ekonomi dan Peningkatan Kualitas Pelayanan Publik (Studi Pemekaran Kabupaten Kepulauan Meranti dari Kabupaten Bengkalis) . Pekanbaru: JOM Fekon.

Kuncoro, dkk. 2014. Membangun Kalimantan Potensi daerah, Pusat Pertumbuhan, dan Strategi. Yogyakarta: Gadjah Mada University Press.

Laporan Realisasi Anggaran Belanja Daerah. Kementerian Keuangan, Direktorat Jendral Perimbangan Keuangan: http://www.djpk.kemenkeu.go.id/, di akses pada 5 Agustus 2020

Novianto, Riko dan Rafiudin Hanafiah .2015. Pengaruh Pendapatan Asli Daerah, Dana Perimbangan dan Kinerja Keuangan Terhadap Alokasi Belanja Modal pada Pemerintah Kabupaten/Kota di Provinsi Kalimantan Barat. Cirebon: Jurnal Ekonomi ISSN: 23027169 Vol. 4 No. 1 Januari-Juni 2015.

Ritonga, dan Irwan Taufik. 2014. Analisis Laporan Keuangan Pemerintah Daerah.Yogyakarta: Lembaga Kajian Manajemen Pemerintah Daerah. .

Yacob, Yarlina . 2012. Pengaruh Tingkat Pengangguran terhadap Tingkat Kemiskinan Kabupaten/Kota di Provinsi Kalimantan Barat Volume 8, Nomor 3. Provinsi Kalimantan Barat: Jurnal eksos ISSN 1693 - 9093. 
